\section{Life-Threatening Arrhythmia During Automated Atrial Capture Management Pacing}

Kyoichiro Yazaki, MD; Morio Shoda, MD; Shohei Kataoka, MD; Miwa Kanai, MD; Satoshi Higuchi, MD; Daigo Yagishita, MD; Koichiro Ejima, MD; Nobuhisa Hagiwara, MD

A 57-year-old male who was implanted with a cardiac resynchronization therapy defibrillator (CRT-D; Viva $^{\mathrm{TM}}$ XT; Medtronic, Minneapolis, MN, USA) for systolic dysfunction experienced a ventricular tachycardia (VT) storm during heart failure hospitalization. No definitive cause was detected; however, electrocardiogram monitoring demonstrated atriobiventricular pacing at the beginning (Figure [A]) and a subsequent rhythm change due to atrial capture management ( $\mathrm{ACM}^{\mathrm{TM}}$; Medtronic; Figure [B]), ${ }^{1}$ followed by a sudden VT (Figure [C]). ACM stimulation seemed to directly induce the VT; however, QRS morphology at VT onset (Figure [C], red circle) was the same as that of the premature ventricular beat (Figure [B], blue circle) and no premature ventricular stimulation preceded the VT, indicating that the VT was not directly induced by the electrical stimulation of the ACM algorithm, but rather by a hemodynamic change during ACM in the absence of biventricular pacing. After ACM discontinua- tion, no further VT was recorded under intravenous amiodarone and nifekalant, and another non-sustained VT was induced by a challenge test of cardiac resynchronization therapy discontinuation.

\section{Disclosure}

N.H. is a member of Circulation Journal's Editorial Team. M.S. and K.E. belong to an endowed department that is sponsored by Biotronik, Medtronic, Boston Scientific and Abbott. The remaining authors have no conflicts of interest to declare.

\section{IRB Information}

The present study was approved by Tokyo Women's Medical University Ethics Committee (Reference no. 4152-R2).

\section{Reference}

1. Sperzel J, Milasinovic G, Smith TW, Mead H, Brandt J, Haisty WK, et al. Automatic measurement of atrial pacing thresholds in dual-chamber pacemakers: Clinical experience with atrial capture management. Heart Rhythm 2005; 2: 1203-1210.

Received January 24, 2021; revised manuscript received February 2, 2021; accepted February 6, 2021; J-STAGE Advance Publication released online March 13, 2021 Time for primary review: 4 days

Department of Cardiology, Tokyo Women' Medical University, Tokyo, Japan

Mailing address: Morio Shoda, MD, Department of Cardiology, Tokyo Women's Medical University, 8-1 Kawada-cho, Shinjuku-ku, Tokyo 162-8666, Japan. E-mail: shoda.morio@twmu.ac.jp

All rights are reserved to the Japanese Circulation Society.

For permissions, please e-mail: cj@j-circ.or.jp

ISSN-1346-9843

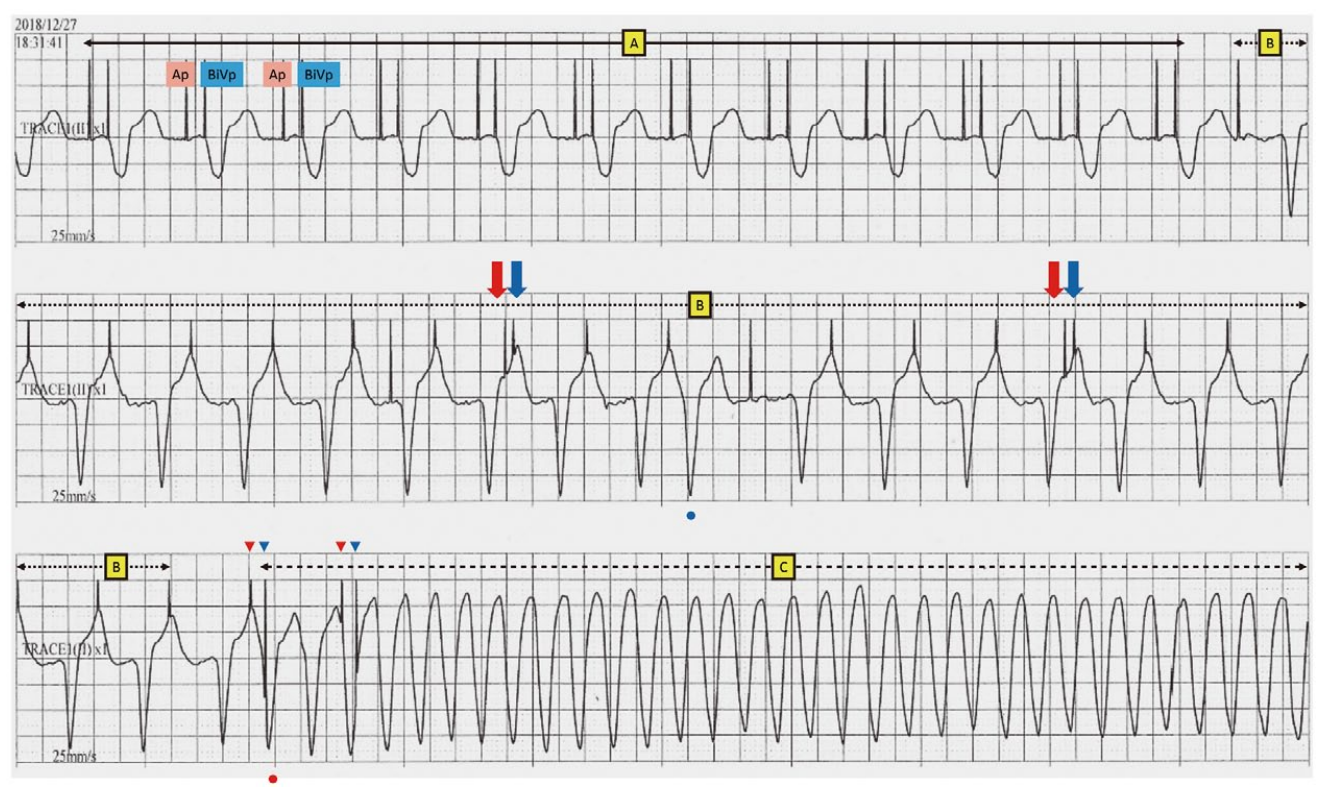

Figure. Electrocardiogram during atrial capture management (ACM) followed by a ventricular tachycardia (VT). [A] The baseline rhythm is atrial pacing (Ap)-biventricular pacing at 80 beats/min with an atrioventricular (AV) delay of $130 \mathrm{~ms}$. [B] ACM with $\mathrm{Ap}$-ventricular sensing at 95 beats/min and a prolonged AV delay of $295 \mathrm{~ms}$. The blue circle indicates the premature ventricular beats. Double arrows indicate an atrial test pulse (red) and atrial backup stimulus (blue) from the ACM. [C] The VT documented during the ACM. The red circle indicates the onset of the VT. Double triangles indicate crosstalk stimulation, with the blue triangles indicating safety pacing. 